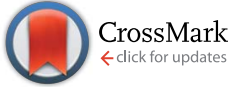

Cite this: RSC Adv., 2017, 7, 468

\title{
Silicone elastomers with covalently incorporated aromatic voltage stabilisers $\dagger$
}

\begin{abstract}
A. H. A. Razak ${ }^{a b}$ and A. L. Skov ${ }^{\star a}$
When optimising dielectric elastomers (DEs) a conflict exists, namely that for large achievable actuation strains softness is required, but with increased softness electrical breakdown strength decreases. Herein, soft dielectric silicone elastomers with increased electrical breakdown strength, due to the incorporation of an aromatic voltage stabiliser, were prepared by cross-linking synthesised polydimethylsiloxanepolyphenylmethylsiloxane (PDMS-PPMS) copolymers. PPMS possesses voltage stabilisation capabilities but is immiscible in PDMS, and thus the copolymerisation of the two components was necessary for homogeneity. Concentrations of the voltage stabiliser were varied by changing the molecular weights of the PPMS in the copolymer. The developed elastomers were inherently soft with enhanced electrical breakdown strengths, due to delocalised $\pi$-electrons of the aromatic constituent. An optimum concentration was found for the voltage stabilisation effect. The relative permittivities of the PDMS-PPMS elastomers varied from 3.4 to 3.9 and therefore were also improved from pure PDMS elastomers. The elastomers were furthermore non-conductive and possessed low dielectric losses. These properties are evaluated as favourable for soft actuation.
\end{abstract}

Received 26th October 2016 Accepted 13th November 2016

DOI: $10.1039 / c 6 r a 25878 f$

www.rsc.org/advances breakdown strength. In this electrical field the maximum theoretical actuation strain is achieved under the assumption that the elastomer is highly extensible and does not break down mechanically prior to electrical breakdown:

$$
s_{\max }=\frac{-\varepsilon_{\mathrm{r}} \varepsilon_{0}}{Y} E_{\mathrm{BD}^{2}}^{2}
$$

elastomers ${ }^{1}$ or other elastomers such as acrylics, polyurethanes and natural rubber. ${ }^{2}$ The actuation performance of a DE at a given voltage $(V)$ can be improved by enhancing the relative permittivity $\left(\varepsilon_{\mathrm{r}}\right)$ or by reducing the Young's modulus $(Y)$. These handles are obvious from the actuation equation derived by Pelrine et al., ${ }^{3}$ which relates the actuation strain $(s)$ to the mentioned parameters via:

$$
s=\frac{-\varepsilon_{\mathrm{r}} \varepsilon_{0}}{Y}\left(\frac{V}{d}\right)^{2}
$$

where $\varepsilon_{0}=8.85 \times 10^{-12} \mathrm{~F} \mathrm{~m}^{-1}$ is the permittivity of free space. The largest achievable electrical field over the dielectric elastomer before electrical failure $\left(E_{\mathrm{BD}}\right)$ is denoted the electrical

${ }^{a}$ Danish Polymer Centre, Department of Chemical and Biochemical Engineering, Technical University of Denmark, Building 227, 2800 Kgs. Lyngby, Denmark. E-mail: al@kt.dtu.dk

${ }^{b}$ Faculty of Engineering Technology, University of Tun Hussein Onn Malaysia, 86400 Parit Raja, Batu Pahat, Johor, Malaysia

† Electronic supplementary information (ESI) available: Number of PDMS-PPMS repeating units, stoichiometric ratios of synthesised copolymer and cross-linking, theoretical and realised molar concentrations of phenyl groups, ${ }^{1} \mathrm{H}-\mathrm{NMR}$ spectra of copolymers, SEM images, electrical breakdown strength and Weibull parameters as function of Young's moduli, and UV/Vis spectra. See DOI: $10.1039 /$ c6ra25878f
However, this strain is not always possible to achieve, since the elastomer may undergo electro-mechanical instability (EMI) which results in premature breakdown. ${ }^{4-7}$ The EMI effect is most common for elastomers with strain-softening behaviour. In the following this effect is ignored, since all investigated elastomers have strain-hardening behaviour. Thus, the maximum achievable strain will be described by eqn (2). Furthermore, it also requires that the electrodes do not contribute to the elastic modulus, whilst they should also be stretchable to the same extent as the elastomer. ${ }^{8}$

As solutions to enhanced relative permittivity, several works have been performed on elastomers by adding titaniu$\mathrm{m}(\mathrm{Iv})$ oxide $\left(\mathrm{TiO}_{2}\right),{ }^{\mathbf{9}, 10}$ barium titanate $\left(\mathrm{BaTiO}_{3}\right)^{1 \mathbf{1 1}}$ and calcium copper titanate $\left(\mathrm{CaCu}_{3} \mathrm{Ti}_{4} \mathrm{O}_{12}\right) \cdot{ }^{12}$ Silicone elastomer composites are usually relatively stiff and lead to significant losses, ${ }^{\mathbf{1}}$ and as alternatives to elastomers with improved permittivity, chemical functionalisation, via the covalent grafting of dipoles such as trifluoropropyl, ${ }^{13} p$-nitroaniline ${ }^{14}$ or azide groups ${ }^{15,16}$ to the silicone backbone, has been investigated. Recently, a novel method for introducing high-permittivity liquids into silicone elastomers was developed, and these elastomers were shown to possess high dielectric permittivity. ${ }^{17,18}$ 
As mentioned previously, another approach to improving actuation performance is reducing the Young's modulus. This can be achieved by either pre-straining externally, using a stiff supporting structure, or pre-straining internally, via an interpenetrating polymer network (IPN) ${ }^{19,20}$ or by creating bimodal networks with reduced cross-linking density in the elastomer matrix..$^{21,22}$ The mentioned elastomers with high relative permittivity and a low Young's modulus improve actuation performance at a given voltage, but these optimised elastomers often possess relatively low electrical breakdown strength. For a given elastomer system (i.e. elastomer matrix and filler) the electrical breakdown strength decreases when the Young's modulus is decreased. ${ }^{9}$

Increasing the electrical breakdown strength of DEs allows for greater actuation, due to the possibility of utilising larger electrical fields without failure. ${ }^{3,23}$ For DEs, several mechanisms lead to electrical breakdown, namely partial discharge $e^{24}$ and electromechanical ${ }^{25}$ and electrothermal breakdown. ${ }^{26,27}$ Multiple studies on pre-strained DE electrical breakdown have been conducted, with the main emphasis on reliability and the effect of electrical breakdown strength on external properties such as effective electrode configurations, ${ }^{28,29}$ elastomer processing techniques ${ }^{30}$ and pre-stretching methods. ${ }^{3,23,29}$ As an alternative approach to enhancing electrical breakdown strength, blending in additives with a voltage-stabilising effect or via polymer structure modifications remains unexplored for dielectric elastomers.

Electron-trapping effects have been investigated previously by including aromatic voltage stabilisers in minute concentrations in polymers, mainly polyethylene (PE), with the purpose of reducing power loss for high-voltage insulation cables. ${ }^{31-33}$ Aromatic voltage stabilisers, which have delocalised $\pi$-electrons, trap energetic electrons and create radicals, as they interrupt the distribution of the $\pi$-electron cloud. ${ }^{34}$ For high-voltage insulation cables, Yamano et al. ${ }^{31}$ increased the electrical breakdown strength in PE by using aromatic azo-compounds which had six different side groups with electron-acceptors $\left(\mathrm{NO}_{2}{ }^{\circ}, \mathrm{CN}^{*}\right)$ or electron-donors $\left(\mathrm{NH}_{2}{ }^{\circ}, \mathrm{CH}_{3}{ }^{\circ}, \mathrm{OH}^{*}\right)$. The PE composite containing the azo-compound with $(\mathrm{OH})_{2}$ and $\mathrm{NO}_{2}$ side groups with a remarkably low concentration of $1 \times 10^{-5} \mathrm{~mol} \mathrm{~g}^{-1}$ had the highest electrical breakdown strength, improving by $48 \%$ compared to the PE without an additive. This indicates that both electron donating $\left(\mathrm{OH}^{*}\right)$ and accepting $\left(\mathrm{NO}_{2}{ }^{\circ}\right)$ groups efficiently increase electrical breakdown strength, due to the increased polarity in the aromatic group and thus lower excitation energies. Yamano ${ }^{32}$ enhanced further electrical breakdown strength in PE with acene compounds (naphthalene, anthracene, tetracene and pentacene) as aromatic voltage stabilisers.

However, utilising aromatic voltage stabilisers of any kind as a silicone additive will unavoidably cause phase separation of the resulting mixture. Preventing this on both the macro and the micro scale during preparation, as well as during actuation, is a key requirement for long DE lifetimes. ${ }^{33}$ The effect of electron-trapping by phenyl groups, so-called 'homo-aromatics', in a silicone elastomer is illustrated in Fig. 1. Electrons in the presence of an electrical field accumulate initially at the interfacial boundary between the film and the electrode, as shown in Fig. 1(b). The electrons then migrate and are trapped in the a

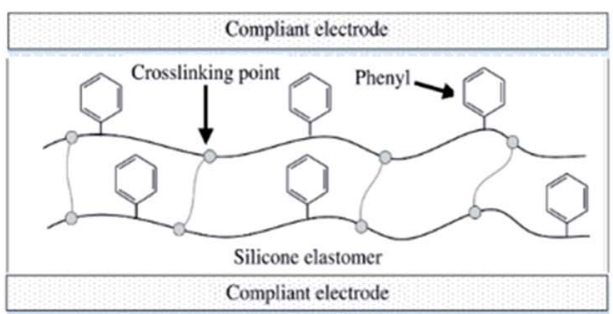

d

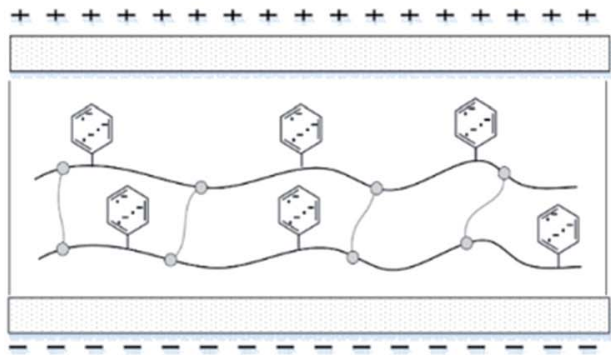

b
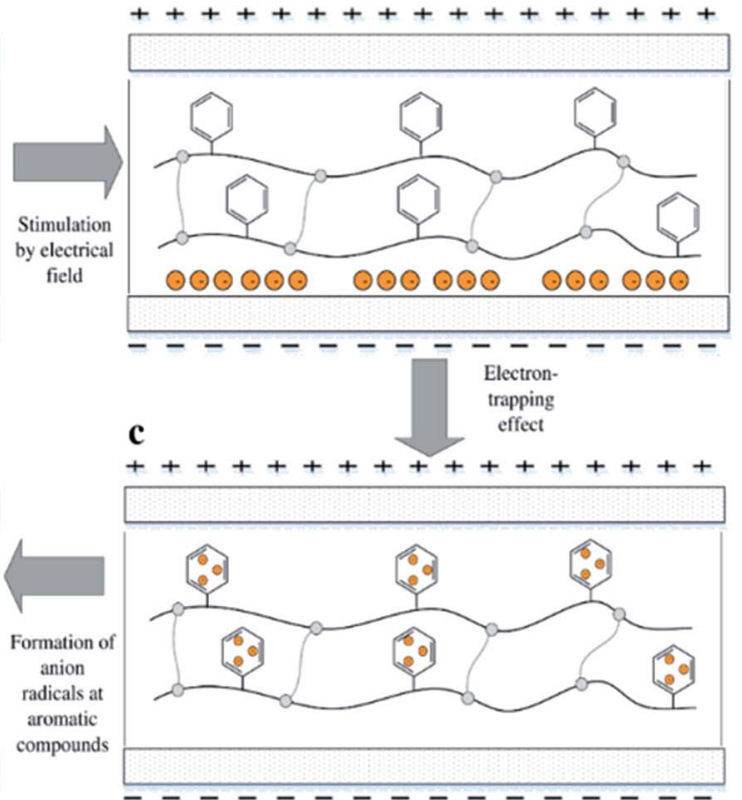

Fig. 1 The enhancement of electrical breakdown strength due to electron-trapping: (a) a silicone elastomer with an aromatic group grafted to the silicone backbone and a coating of compliant electrodes on the top and bottom surfaces. (b) The existence of electrons at the interfaces between the elastomer and the compliant electrode in the presence of an electrical field. (c) The electron-trapping effect as a consequence of a collision between electrons and the phenyl group. (d) The formation of anion radicals resulting from the disturbance of the cloud of $\pi$ electrons of the phenyl group. 
phenyl group, as seen in Fig. 1(c). When electrons migrate and collide with the homo-aromatic group, they disturb the cloud of pi-electrons in the aromatic group, and this results in the formation of electron-accepting radicals, as shown in Fig. 1(d). The depth of the electron trap is highly influenced by the type of radical, ${ }^{34}$ where the depth for the aromatic group with the radical of an electron-accepting type is larger than that of the aromatic group without a radical. ${ }^{32,34}$ The trapped electrons act as negative space charges in the elastomer, causing a decrease in electrical field strength on the cathode. ${ }^{32}$ This decreased electrical field strength then reduces electron migration from the cathode. The trapped electrons remain in the film bulk and therefore delay electrical breakdown; thus, increased electrical breakdown strength is achieved.

In this work, the voltage stabilisation effect of PPMS in cross-linked PDMS-PPMS copolymers is investigated, while cross-linked materials are characterised mechanically and dielectrically.

\section{Experimental}

\section{Materials}

Telechelic vinyl-terminated polydimethylsiloxanes (V-PDMS) were DMS-V31, DMS-V25, DMS-V22 and DMS-V21, with a number average molecular weight $\left(M_{\mathrm{n}}\right)$ of $28,17.2,9.4$ and $6 \mathrm{~kg} \mathrm{~mol}{ }^{-1}$, respectively. Telechelic hydride-terminated polyphenylmethylsiloxanes (H-PPMS) were PMS-H03 $\left(M_{\mathrm{n}}=0.4 \mathrm{~kg}\right.$ $\left.\mathrm{mol}^{-1}\right)$ and PMS-H11 $\left(M_{\mathrm{n}}=1 \mathrm{~kg} \mathrm{~mol}{ }^{-1}\right)$. The catalyst was a platinum-divinyl-tetramethyl disiloxane complex [SIP6830.3] containing $3.25 \%$ of platinum in xylene. The vinyl-functional cross-linker was methyl-hydrosiloxane-dimethylsiloxane copolymer [VDT-431] $\left(M_{\mathrm{n}}=28 \mathrm{~kg} \mathrm{~mol}^{-1}, 15\right.$-functional). All polymers, cross-linkers and catalysts were purchased from Gelest Inc. Fumed silica (SIS6962.0) was purchased from Fluorochem.

\section{Synthesis of PDMS-PPMS block copolymers}

PDMS-PPMS block copolymers were prepared from the hydrosilylation of hydride-terminated PPMS and vinyl-terminated PDMS at room temperature in the presence of a platinum $(\mathrm{Pt})$ catalyst, as shown in Scheme 1. The synthesised block copolymer has $X+1$ blocks of phenylmethylsiloxane and $X$ blocks of dimethylsiloxane.

The procedure to synthesise PDMS-PPMS block copolymers was taken from A. Razak et al. ${ }^{35}$ The required amount of hydride-terminated PPMS was added based on a targeted molecular weight $\left(M_{\mathrm{n}, \mathrm{T}}\right)$ of $30 \mathrm{~kg} \mathrm{~mol}^{-1}$ of the copolymer (refer to ESI 1, eqn (1) $\dagger$ ). The mixture containing V-PDMS, H-PPMS and $30 \mathrm{ppm}$ of the Pt catalyst was speed-mixed at $3000 \mathrm{rpm}$ for $5 \mathrm{~min}$. The stoichiometric ratio was calculated based on the number of PDMS-PPMS repeating units, $X$ (see ESI 1, eqn (2) $\dagger$ ).

\section{Cross-linking and sample preparation}

All PDMS-PPMS block copolymer samples were cross-linked with the vinyl-functional 15 -functional cross-linker. The stoichiometric ratio for cross-linking $\left(r_{2}\right)$ was 1.5 , with an excess of cross-linker (see ESI 2, eqn ( 3$) \dagger$ ). Blends containing copolymer, cross-linker, $30 \mathrm{ppm}$ of $\mathrm{Pt}$ catalyst and 25 parts per hundred rubber (phr) of silica were speed-mixed at $2500 \mathrm{rpm}$ for 4 minutes.

The final mixtures were casted on Teflon plates for easy release. The cross-linked copolymer films were prepared in thicknesses of approximately $1 \mathrm{~mm}$ (thick film) and $100 \pm 20$ $\mu \mathrm{m}$ (thin film). Thick films were used to measure linear viscoelasticity (LVE), the stress-strain relationship and dielectric properties. All films were placed in a vacuum oven at $23{ }^{\circ} \mathrm{C}$ for 4 to 8 hours, due to trapped air during fabrication, and were thereafter cured at $40{ }^{\circ} \mathrm{C}$ for 12 hours to ensure proper film formation. The curing process was continued at $150{ }^{\circ} \mathrm{C}$ for 8 to 12 hours. Subsequently, all films were post-cured at $200{ }^{\circ} \mathrm{C}$ for 2 hours to remove all volatiles. ${ }^{36,37}$

The cross-linked PDMS-PPMS copolymer is referred as a PDMS-PPMS elastomer. Samples were named based on repeating numbers of PDMS and PPMS as $n$ DMS_mPMS. The realised molar concentrations of the phenyl group $\left(C_{\mathrm{C}_{6} \mathrm{H}_{5}}\right)$ were calculated from the ratio of the mole number of the phenyl group to the total mass of PDMS and PPMS. The mole number of the phenyl group was determined based on integration areas and $\mathrm{H}$ 's numbers of $\mathrm{CH}_{3}-\mathrm{Si}-\mathrm{C}_{5} \mathrm{H}_{5}$ and $\mathrm{Si}-\left(\mathrm{CH}_{3}\right)_{2}$ in ${ }^{1} \mathrm{H}-\mathrm{NMR}$

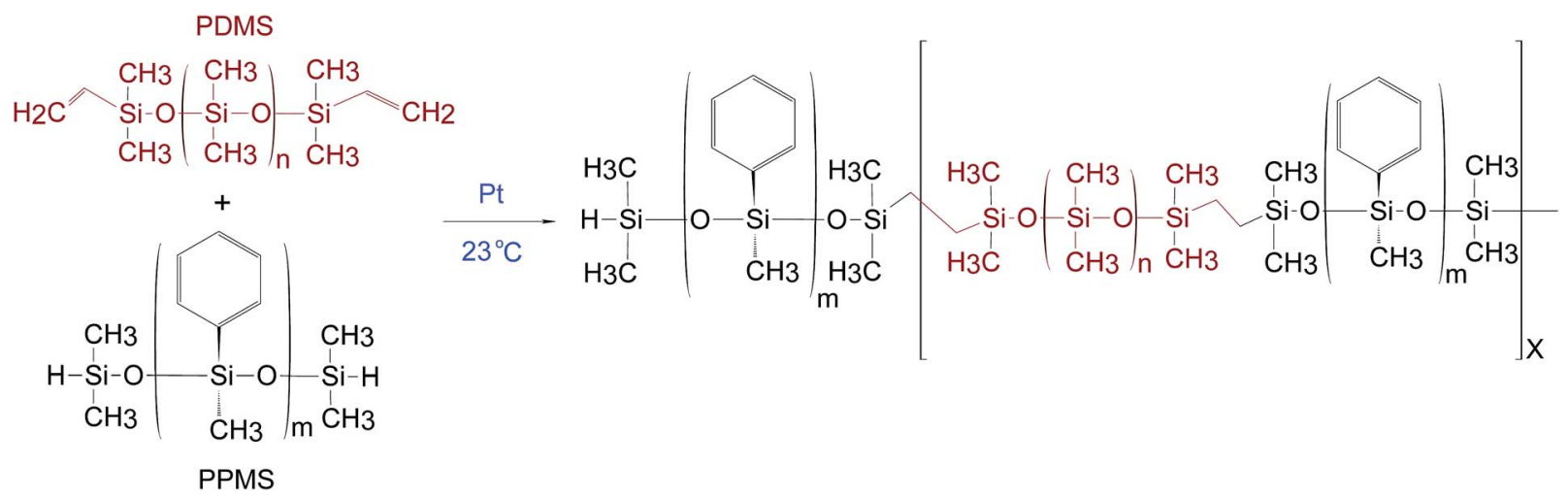

Scheme 1 The hydrosilylation reaction utilised when preparing the PDMS-PPMS block copolymer with a stoichiometric ratio of $r=(X+1) / X$, where $m$ is the number of repeating phenylmethylsiloxane units in PPMS ( $m=2$ and 6$)$ and $n$ is the number of repeating dimethylsiloxane units in PDMS ( $n=377,231,126$ and 80). 
(refer to ESI 3, eqn (4-7)†). Details of the PDMS-PPMS copolymers are presented in Table 1.

\section{Instrumentation}

Degree of conversion of vinyl groups in the synthesis of PDMS-PPMS copolymer. The synthesised copolymer was a telechelic hydride-functional PDMS-PPMS copolymer. The degree of conversion of the PDMS vinyl group from the hydrosilylation of hydride-terminated PPMS and vinyl-terminated PDMS was determined via proton nuclear magnetic resonance spectroscopy $\left({ }^{1} \mathrm{H}-\mathrm{NMR}\right)$ by observing the disappearance of vinyl peaks in the NMR spectra. The NMR equipment utilised for ${ }^{1} \mathrm{H}$ was a Bruker $300 \mathrm{MHz}$ NMR. The number of scannings per sample was 128. The samples were prepared at a concentration of $100 \mathrm{mg} \mathrm{mL}{ }^{-1}$ in deuterated chloroform $\left(\mathrm{CDCl}_{3}\right)$.

Number average molecular weight. The number average molecular weights $\left(M_{\mathrm{n}}\right)$ of the copolymers were determined from size-exclusive chromatography (SEC). SEC was performed on a Viscotek GPCmax VE-2001 instrument equipped with a Viscotek TriSEC Model 302 triple detector using two PLgel mixed-D columns from Polymer Laboratories. The copolymer concentrations were between 2 and $3 \mathrm{mg} \mathrm{mL}^{-1}$ in toluene, and solutions were run at $35{ }^{\circ} \mathrm{C}$ at an elution rate of $1 \mathrm{~mL} \mathrm{~min}^{-1}$. Molecular weight distributions were calculated using WinGPC Unity 7.4.0 software and linear PDMS standards acquired from Polymer Standards Service GmbH.

Electrical breakdown strength. The measurement of electrical breakdown strength was performed on an in-house-built device based on international standards (IEC 60243-1 (1998) and IEC 60243-2 (2001)). Samples were prepared with a thickness of less than $110 \mu \mathrm{m}$. The film was slid between two spherical metal electrodes (diameter of $20 \mathrm{~mm}$ ). The electrical breakdown measurement was taken at the point of contact with a stepwise increasing voltage applied (50-100 V per step) at a rate of $0.5-1$ steps per s. The electrical breakdown measurement was repeated 12 times for each sample, and the average of these values was then stated as electrical breakdown strength.

Dielectric properties. Dielectric properties were measured by dielectric spectroscopy performed on a Novocontrol Alpha-A high-performance frequency analyser (Novo-control Technologies

Table 1 Sample details and realised molar concentrations of the phenyl group of cross-linked PDMS-PPMS copolymers

\begin{tabular}{llll}
\hline $\begin{array}{l}\text { Vinyl- } \\
\text { functional } \\
\text { PDMS }\end{array}$ & $\begin{array}{l}\text { Hydride- } \\
\text { functional } \\
\text { PPMS }\end{array}$ & $\begin{array}{l}\text { PDMS-PPMS } \\
\text { copolymer } \\
(n \text { DMS_mPMS })\end{array}$ & $\begin{array}{l}\text { Realised concentration } \\
\text { of phenyl groups } \\
{\left[10^{-4} \mathrm{~mol} \mathrm{~g}^{-1}\right]}\end{array}$ \\
\hline DMS-V31 & PMS-H03 & 377DMS_2PMS & 5.0 \\
DMS-V25 & & 231DMS_2PMS & 6.9 \\
DMS-V22 & & 126DMS_2PMS & 7.8 \\
DMS-V21 & & 80DMS_2PMS & 8.4 \\
DMS-V31 & PMS-H11 & 377DMS_6PMS & 8.7 \\
DMS-V25 & & 231DMS_6PMS & 9.8 \\
DMS-V22 & & 126DMS_6PMS & 15 \\
DMS-V21 & & 80DMS_6PMS & 20
\end{tabular}

$\mathrm{GmbH} \& \mathrm{Co}$. KG, Germany) operating in the frequency range $10^{-1}$ to $10^{6} \mathrm{~Hz}$ at $23^{\circ} \mathrm{C}$. The electrode diameter was $20 \mathrm{~mm}$. The sample was sandwiched between two gold-coated plates prior to the measurement.

Linear viscoelastic (LVE) properties. Prepared films were characterised at $23{ }^{\circ} \mathrm{C}$ using an advanced rotational rheometer from TA Instruments (ARES-G2). The utilised parallel plates had a diameter of $25 \mathrm{~mm}$. The axial force ranged from 5 to $12 \mathrm{~N}$, depending on the samples, to ensure sufficient contact between the plate and the sample (diameter of $25 \mathrm{~mm}$ ). The strain and frequency in the linear regime were $2 \%$ and $10^{-2}$ to $10^{2} \mathrm{~Hz}$, respectively.

Stress-strain relationship. Tensile strengths and elongations at breaking, as well as the Young's moduli at a 5\% strain, were measured in extensional rheological tests. The rheological test was performed on an ARES-G2 rheometer from TA Instruments by means of an SER2 universal testing platform consisting of two rotating drums with a diameter of $10.3 \mathrm{~mm}$, with the lateral offset of the centre axis of these two drums at $12.7 \mathrm{~mm}$. The sample, which was a rectangular strip of $6 \mathrm{~mm}$ (width), $30 \mathrm{~mm}$ (length) and $1 \mathrm{~mm}$ (thickness), elongated within a confined length $(L=12.7 \mathrm{~mm})$ by winding up the strip with the two rotary drums. The ends of the strip were secured by means of strong glue to the surfaces of the drums. For incompressible samples, the ends of the strip moved at speed $\left[v_{\text {end }}=(L / 2) \mathrm{d} \varepsilon_{\mathrm{H}} / \mathrm{d} t\right]$. Integrating this speed from an initial length $\left(L_{\mathrm{O}}\right)$ to the final length $\left(L_{\mathrm{f}}\right)$ led to an exponential increase in sample length over time $L(t)=L_{\mathrm{o}} \exp \left[\left(\mathrm{d} \varepsilon_{\mathrm{H}} / \mathrm{d} t\right) t\right]$, and so the final Hencky strain $\left(\varepsilon_{\mathrm{H}}\right)$ can thus be expressed as follows: $\varepsilon_{\mathrm{H}}=\ln \left[L_{\mathrm{f}} / L_{\mathrm{o}}\right]$. Here, engineering stress and strain were used for the stress-strain relationship. Engineering strain was calculated from the measured Hencky strains, and engineering stress was calculated from the measured torque over a cross-sectional area of the sample (refer to eqn $(8-12) \dagger$ in ESI 4 for engineering stress and strain, respectively).

Scanning electron microscopy (SEM) images. The morphologies of the cross-linked copolymers and the reference elastomer were examined via scanning electron microscopy (SEM) (FEI Inspect S, USA). The samples were cross-sectional films and were firstly immersed in liquid nitrogen for a few minutes, then broken and deposited on a sample holder. All samples were coated with gold under vacuum conditions before testing. Energy-dispersive X-ray (EDX) spectroscopy (Oxford INCAWave 500 , UK) was applied to detect the element distribution profile on the surface of the samples.

UV/Vis absorbance. The presence of phenyl groups in the cross-linked copolymers was detected from the absorbance energy of ultraviolet (UV) or visible light (Vis). Energy absorbance from UV/Vis light was measured by an UV/Vis spectrometer from BMG Labtech (SPECTROstar Omega). The wavelength range of the UV/Vis spectrometer was from 220 to $1000 \mathrm{~nm}$, while optical density (OD) range was between 0 and 4 OD with an accuracy of $<1 \%$ at 2 OD. Energy absorbance was measured within wavelengths of 220 to $350 \mathrm{~nm}$. These measurements were performed on eight wells of a Nunc 96-Well LockWell $^{\mathrm{TM}}$ PolySorp module plate from Thermo Scientific for thin films with an approximate thickness of $100 \mu \mathrm{m}$. 
a

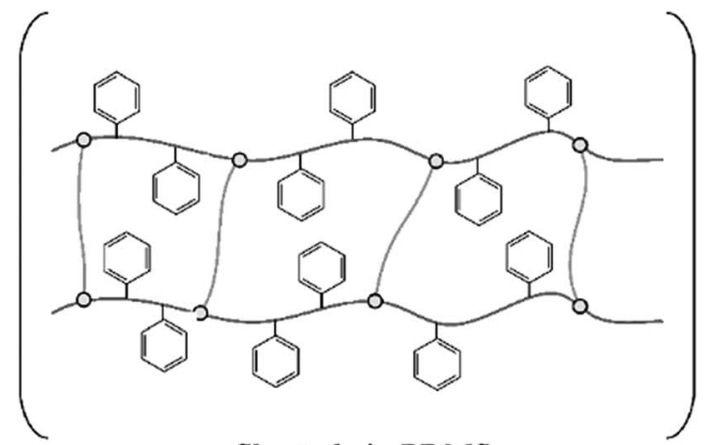

Short-chain PDMS-

PPMS elastomer $(\mathrm{m}=2)$ b

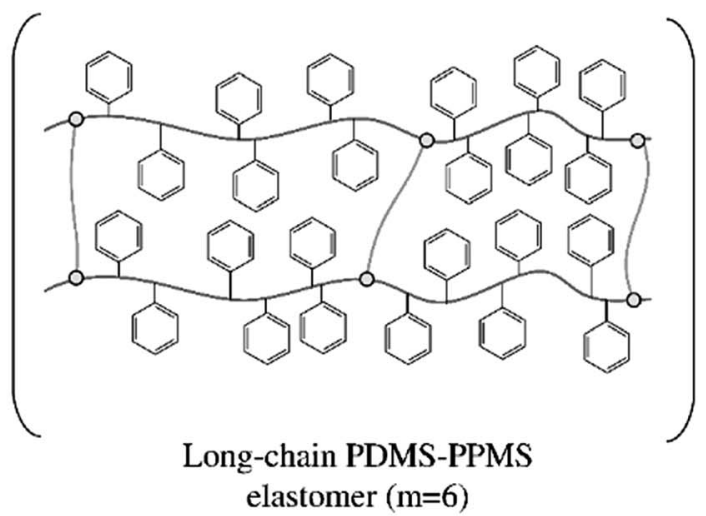

Fig. 2 Illustration of a cross-linked PDMS-PPMS copolymer with (a) short chain and (b) long chain.

\section{Results and discussion}

The targeted elastomers with covalently grafted voltage stabilisers are shown in Fig. 2. In order to realise these elastomers, copolymers were first synthesised and characterised before being cross-linked into elastomers.

\section{Synthesised PDMS-PPMS copolymers}

Determined molecular weights of synthesised PDMS-PPMS copolymers are shown in Table 2. All copolymers have low polydispersity indexes ( $\mathrm{PDI} \leq 2.1$ ). The disappearance of the $\mathrm{Si}-$ $\mathrm{CH}_{2}=\mathrm{CH}_{2}$ bond signal at 5.8-6.2 ppm was confirmed by ${ }^{1} \mathrm{H}-$ NMR, to ensure that all vinyl groups in the PDMS had been consumed fully during the hydrosilylation of vinyl-terminated PDMS and hydride-terminated PPMS; refer to ESI 5 for NMR spectra in Fig. S2-9. $\dagger^{1} \mathrm{H}-\mathrm{NMR}$ spectra confirmed that the synthesised PDMS-PPMS copolymers were hydride functional, and all vinyl groups in the PDMS were fully reacted.

\section{Linear viscoelasticity}

To evaluate the effect of the increased concentration of the phenyl group on viscoelastic properties, the prepared elastomers were characterised rheologically, as shown in Fig. 3. This is an important investigation to perform for these systems, since aromatics are well-known to inhibit utilised silylation

Table 2 Average number of molecular weights and actual concentrations of the phenyl group of synthesised PDMS-PPMS copolymers

\begin{tabular}{lll}
\hline $\begin{array}{l}\text { Cross-linked PDMS-PPMS } \\
\text { copolymer }\end{array}$ & $\begin{array}{l}\text { Actual } M_{\mathrm{n}, \mathrm{T}} \\
(\mathrm{kg} \mathrm{mol})\end{array}$ & $\begin{array}{l}\text { Polydispersity index, } \\
\text { PDI }\left(M_{\mathrm{w}} / M_{\mathrm{n}}\right)\end{array}$ \\
\hline 377DMS_2PMS & 32 & 2.1 \\
231DMS_2PMS & 36 & 1.9 \\
126DMS_2PMS & 73 & 1.5 \\
80DMS_2PMS & 39 & 1.8 \\
377DMS_6PMS & 42 & 1.7 \\
231DMS_6PMS & 37 & 1.8 \\
126DMS_6PMS & 82 & 1.6 \\
80DMS_6PMS & 32 & 2.0
\end{tabular}

chemistry. The PDMS-PPMS elastomers show to be well crosslinked and behave elastically, i.e. the inhibiting nature of the phenyl groups did not affect the final properties of the elastomers. The resulting storage moduli $\left(G^{\prime}\right)$ for all elastomers and the reference are between $10^{4}$ and $10^{5} \mathrm{~Pa}$, and they all behave in a similar manner with close-to-identical relaxations. From these results it is obvious that the elastomers maintain network integrity. Relative losses $[\tan (\delta)]$ are comparable to these of commercial silicone elastomers such as Elastosil RT625 from Wacker Chemie. ${ }^{38}$

\section{Stress-strain relationship}

Stress-strain curves and Young's moduli of the cross-linked copolymers are shown in Fig. 4 and 5, respectively. All crosslinked copolymers show increased strain at breaking, compared to the reference (DMS-H31), due to an evident 'plasticising' effect (see Fig. 4). All elastomers are still strainhardening despite being plasticised. The resulting Young's moduli at $5 \%$ strains of the cross-linked copolymers are shown in Fig. 5, and the soft nature of all the elastomers is obvious. Common Young's moduli of silicone elastomers are around

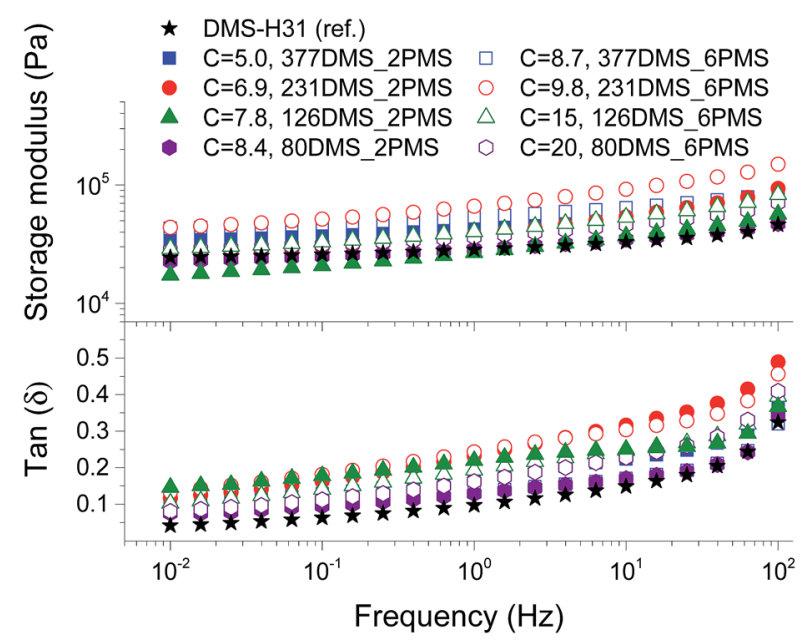

Fig. 3 The storage and $\tan (\delta)$ of cross-linked PDMS-PPMS copolymers at $23^{\circ} \mathrm{C} ; \mathrm{C}$ is in $10^{-4} \mathrm{~mol} \mathrm{~g}^{-1}$. 


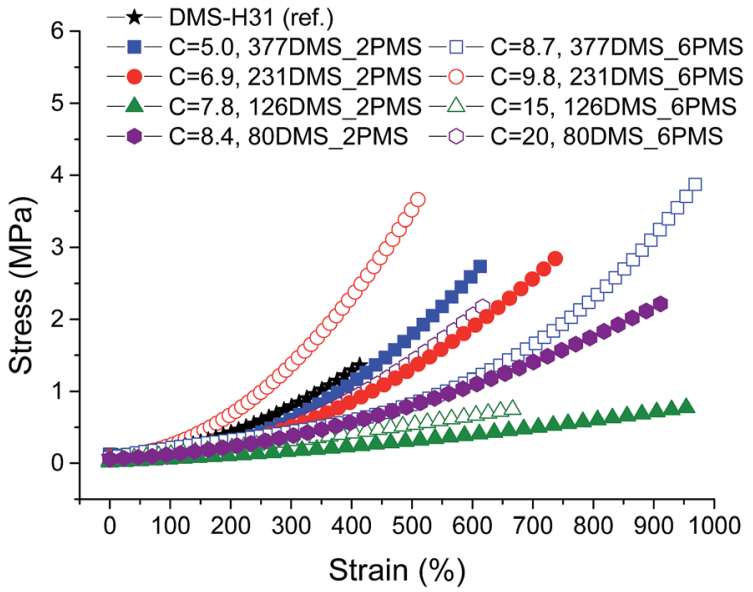

Fig. 4 Stress-strain curves for PDMS-PPMS elastomers with different phenyl group concentrations at $23^{\circ} \mathrm{C}$ (typical standard deviations in tensile measurements were of the order $\pm 5 \%$ ).

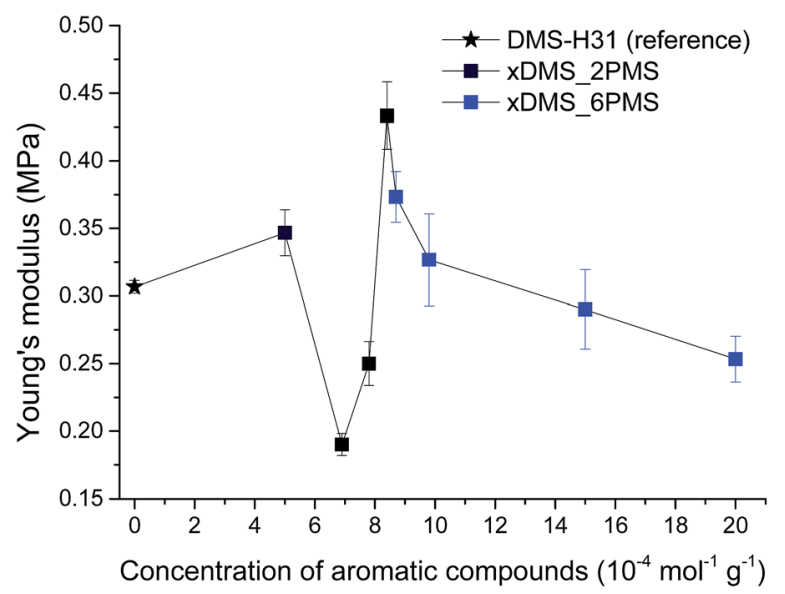

Fig. 5 Young's moduli for the PDMS-PPMS and reference elastomers.

$1 \mathrm{MPa} .^{38}$ Another finding is that the cross-linked copolymer 80DMS_2PMS is slightly stronger than the reference elastomer (DMS-H31), not only with respect to the initial Young's modulus, but also with respect to ultimate strength.

With respect to actuation, elastomers $C=7.8$ and $15 \times$ $10^{-4} \mathrm{~mol} \mathrm{~g}^{-1}$ show the most softness. On the other hand, both elastomers do not possess any significant strain-hardening behaviour. The slightly stronger elastomers $C=8.4$ and $8.7 \times$ $10^{-4} \mathrm{~mol} \mathrm{~g}^{-1}$ show ideal properties for actuation with good, ultimately strain-hardening, behaviour.

Obviously, from the mechanical data, there is no clear trend in mechanical behaviours except that a concentration of around $8.5 \times 10^{-4} \mathrm{~mol} \mathrm{~g}^{-1}$ seems to be the most favourable. This is most likely due to local phase separation, which serves both to stabilise and to plasticise the elastomer, i.e. some regions will be rich in PPMS (rigid zones) and other regions poor (plasticised zones). This can be seen to some extent from SEM imaging of the resulting films with two examples shown in Fig. 6. As investigated by Luo et al., ${ }^{39}$ PDMS shows a distinct triangular pattern whereas PMMS shows a pattern with bent rectangles.
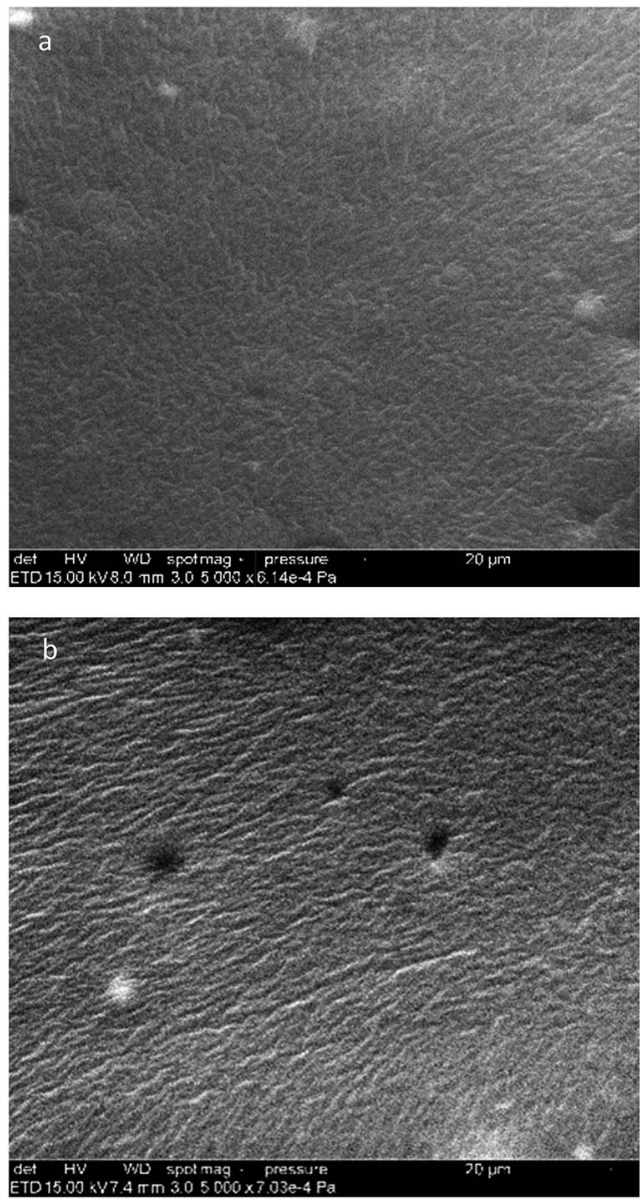

Fig. 6 SEM pictures of two representative samples, namely (a) 377DMS_2PMS and (b) 80DMS_2PMS.

This is illustrated below by the elastomers 377DMS_2PMS and 80DMS_2PMS, wherein sample 377DMS_2PMS shows a distinct PDMS structure while elastomer 80DMS_2PMS has areas with both signatures. SEM pictures of all elastomers can be seen in ESI 6, Fig. S10.†

\section{Dielectric properties}

The conductivity and dielectric properties of the cross-linked PDMS-PPMS copolymers and the reference elastomer are shown in Fig. 7 and 8, respectively. The resulting conductivities indicate that none of the cross-linked copolymers is conductive, as illustrated in Fig. 7. Low conductivity is a key element in the actuation performance of the DE. The relative permittivity of prepared elastomers with short-chain PPMS initially increases and reaches a maximum phenyl group concentration of $6.9 \times$ $10^{-4} \mathrm{~mol} \mathrm{~g}^{-1}$, albeit it decreases thereafter. On the other hand, the relative permittivity of cross-linked copolymers with longchain PPMS decreases in line with an increase in phenyl concentration. The flat curves furthermore indicate that phase separation is not macroscopic but rather limited to the lower microscale or nanoscale. These observations again indicate that micro- or nanoscale phase separation takes place and that the morphology of the elastomers depends strongly on the 


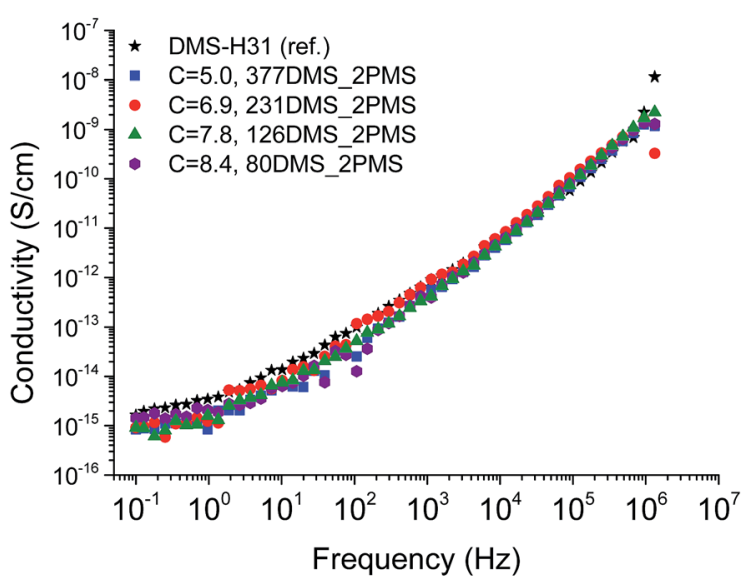

b

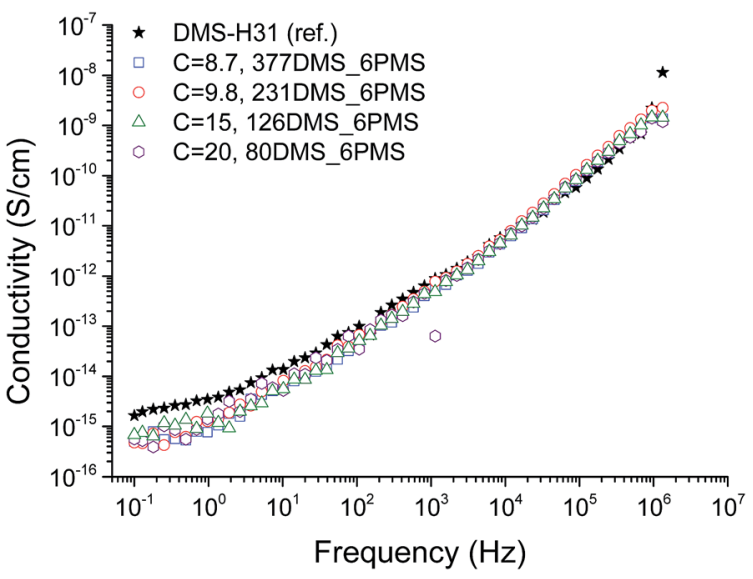

Fig. 7 The conductivity of PDMS-PPMS elastomers with different phenyl concentrations of at $23^{\circ} \mathrm{C}$ : (a) short-chain and (b) long-chain PPMS; $C$ is in $10^{-4} \mathrm{~mol} \mathrm{~g}^{-1}$.

concentration of phenyl groups. Dielectric losses, which are represented by $\tan (\delta)$, are relatively low for all cross-linked copolymers, as shown in Fig. 8. The reference elastomer (DMS-H31) shows low $\tan (\delta)$ as well.

\section{Electrical breakdown and Weibull analysis}

The influence of the concentration of the phenyl group in cross-linked PDMS-PPMS copolymer on electrical breakdown strength was investigated. The resulting electrical breakdown strength of the cross-linked copolymers with different phenyl group concentrations is shown in Fig. 9, namely an optimum electrical breakdown strength $\left(72 \pm 3 \mathrm{~V} \mathrm{\mu m}^{-1}\right)$ occurring at a phenyl concentration of $8.4 \times 10^{-4} \mathrm{~mol} \mathrm{~g}^{-1}$. In other words, electrical breakdown strength has increased $36 \%$ compared to the reference elastomer. The optimum is most likely due to the combination of favourable phase separation and a relatively high concentration of phenyl groups. Stiffness may also affect electrical breakdown strength strongly, ${ }^{9}$ i.e. the electrical breakdown strength of the reference elastomer is low due to the inherently soft nature of silicone elastomers cross-linked from

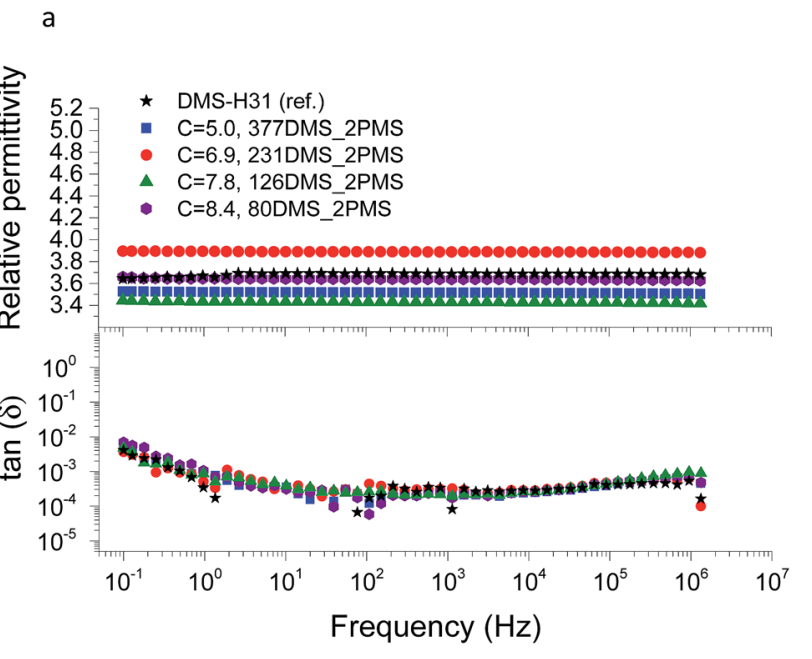

b

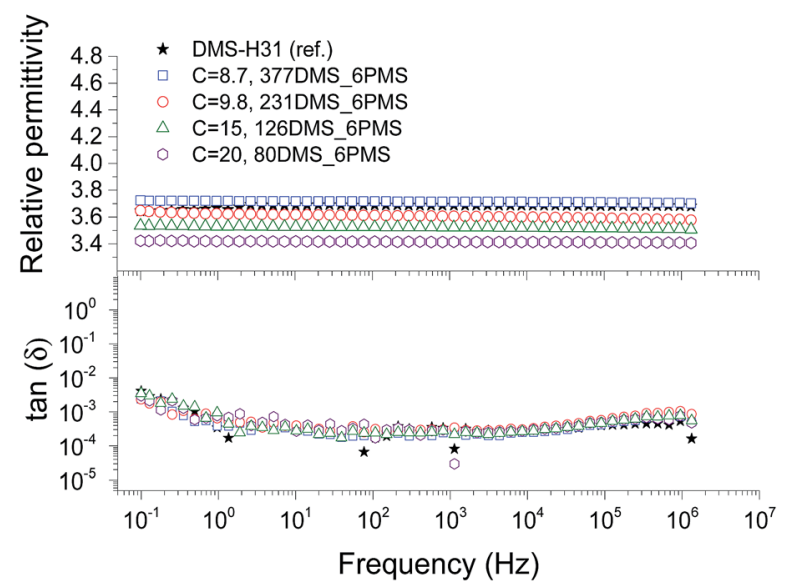

Fig. 8 The dielectric properties of PDMS-PPMS elastomers with different phenyl concentrations at $23^{\circ} \mathrm{C}$ : (a) short-chain and (b) longchain PPMS; $C$ is in $10^{-4} \mathrm{~mol} \mathrm{~g}^{-1}$.

high molecular weight PDMS polymers ${ }^{40}$ and there is a broad amount of variation in the Young's moduli of the prepared elastomers. To evaluate whether the voltage stabilisation effect is

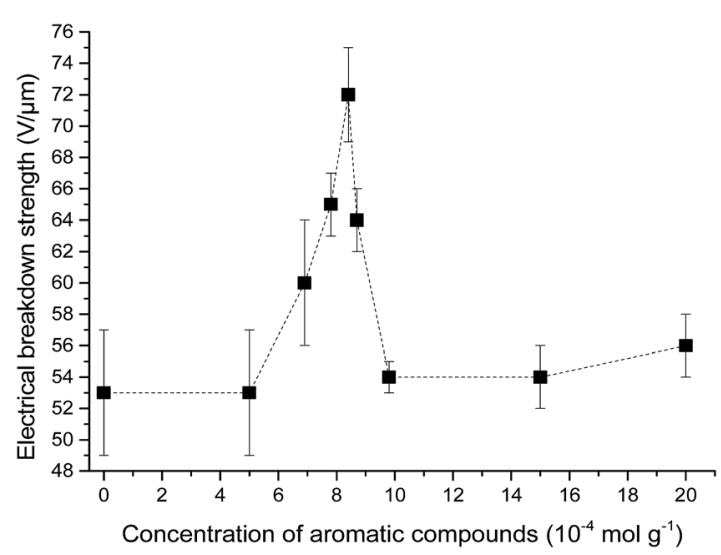

Fig. 9 Electrical breakdown strength of PDMS elastomer and PDMSPPMS copolymers with different phenyl group concentrations. 

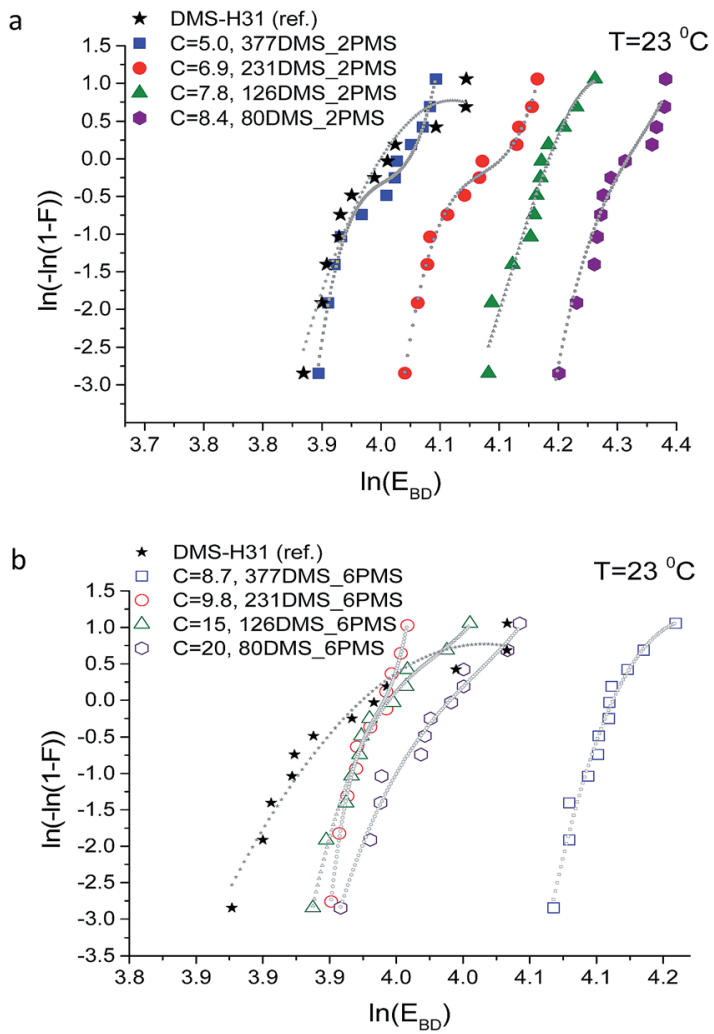

Fig. 10 Weibull plots of PDMS elastomer and PDMS-PPMS copolymers with different phenyl group concentrations: copolymers from (a) short-chain and (b) long-chain PPMS. The dashed lines serve solely as guidelines for the eyes to differentiate between data slopes; $C$ is in units of $10^{-4} \mathrm{~mol} \mathrm{~g}^{-1}$.

rather an effect of increased stiffness, the influence of $Y$ on electrical breakdown strength was investigated. There is no correlation, as seen from ESI 7 in Fig. S11, $\dagger$ which means that the effect is due to the voltage stabilisation effect.

Weibull analysis was used to obtain a further understanding of the electrical reliability of the prepared elastomers. The Weibull probability distribution of failure for all films is shown in Fig. 10. The $\eta$-parameter, which is the Weibull scale parameter, was determined from the Weibull plot as the value at which failure probability, $\ln [-\ln (1-F)]$, was $63.2 \% .^{35}$ The $\beta$-parameter is the Weibull shape parameter, representing the broadness of distribution. The $\eta$-parameter is closely correlated to the mean breakdown voltage. ${ }^{41} \mathrm{~A}$ small value of the Weibull shape parameter indicates that electrical breakdown occurrences are broadly dispersed. ${ }^{\mathbf{4 1}}$

Due to different prepared PDMS-PPMS elastomer film thicknesses, the determined electrical breakdown strengths were normalised based on a reference thickness for better comparison. Normalised dielectric breakdown strength can be determined by: ${ }^{28}$

$$
E_{n}=n^{-\frac{1}{\beta}} E_{0}
$$

where $E_{0}$ is the electrical breakdown strength of a $100 \mu \mathrm{m}$ film, $\beta$ is the Weibull shape parameter and $n$ is relative sample thickness compared to the chosen reference thickness of $\left(t_{0}=\right.$ $100 \mu \mathrm{m})$.

The results for the normalised electrical breakdown strength $\left(E_{n}\right)$, Weibull $\eta$ - and $\beta$-parameters and $R^{2}$ of the linear fits for cross-linked copolymers, including the reference, are summarised in Table 3. Cross-linked PDMS-PPMS copolymers with long-chain PPMS possess lower electrical breakdown strength standard deviation than the copolymers with short-chain PPMS, as illustrated in Table 3. The coefficient of determination $\left(R^{2}\right)$ of all investigated elastomers is above 0.85 , indicating that the measured electrical breakdown strengths correlate well with the fitted regression lines.

The Weibull plots for all samples are shown in Fig. 10. The plotted data in the Weibull probability distribution of failure of elastomers with short-chain PPMS clearly show two domains (refer to Fig. 10(a)). This is an indication of the inhomogeneity of the phenyl group in the PDMS-PPMS matrix containing shortchain PPMS. On the other hand, the Weibull distribution data for the elastomers with long-chain PPMS show one domain with only a small discrepancy at high voltages, thereby indicating better homogeneity of the phenyl group in the PDMS-PPMS matrix.

Weibull parameters $\eta$ and $\beta$ at different phenyl group concentrations are compared and summarised in Fig. 11. One important finding from the values of the Weibull $\beta$-parameter is that the PDMS-PPMS elastomers with long-chain PPMS have larger $\beta$-parameter values compared to the elastomers with short-chain PPMS except at very high phenyl group loadings, where $\beta$ drops. For both types of cross-linked copolymers an optimum $\eta$ parameter value of around $8 \times 10^{-4}$ is found.

Table 3 Electrical breakdown strength at $23^{\circ} \mathrm{C}$, Weibull parameters $\eta$ and $\beta$ and $R^{2}$ of the linear fit for all prepared cross-linked copolymers and the reference

\begin{tabular}{|c|c|c|c|c|c|c|}
\hline $\begin{array}{l}\text { Cross-linked PDMS-PPMS } \\
\text { copolymer }\end{array}$ & $\begin{array}{l}\text { Thickness } \\
(\mu \mathrm{m})\end{array}$ & $\begin{array}{l}\text { Electrical breakdown } \\
\text { strength }\left(\mathrm{V} \mu \mathrm{m}^{-1}\right)\end{array}$ & Weibull $\beta$-parameter & Weibull $\eta$-parameter & $R^{2}$ & $\begin{array}{l}\text { Normalised electrical } \\
\text { breakdown }\left(\mathrm{V} \mu \mathrm{m}^{-1}\right)\end{array}$ \\
\hline DMS-H31 (ref.) & 105 & $53 \pm 4$ & 17 & 55 & 0.85 & $52.9 \pm 3.6$ \\
\hline 377DMS_2PMS & 81 & $53 \pm 4$ & 17 & 55 & 0.85 & $53.7 \pm 3.7$ \\
\hline 231DMS_2PMS & 91 & $60 \pm 4$ & 20 & 61 & 0.91 & $60.1 \pm 3.4$ \\
\hline 126DMS_2PMS & 80 & $65 \pm 2$ & 32 & 66 & 0.94 & $65.5 \pm 2.5$ \\
\hline 80DMS_2PMS & 90 & $72 \pm 3$ & 26 & 73 & 0.92 & $71.9 \pm 3.1$ \\
\hline 377DMS_6PMS & 81 & $64 \pm 2$ & 47 & 65 & 0.89 & $64.1 \pm 1.6$ \\
\hline 231DMS_6PMS & 95 & $54 \pm 1$ & 60 & 54 & 0.94 & $54.0 \pm 1.6$ \\
\hline 126DMS_6PMS & 95 & $54 \pm 2$ & 39 & 55 & 0.88 & $54.0 \pm 1.8$ \\
\hline 80DMS_6PMS & 95 & $56 \pm 2$ & 28 & 57 & 0.94 & $56.1 \pm 2.2$ \\
\hline
\end{tabular}


a

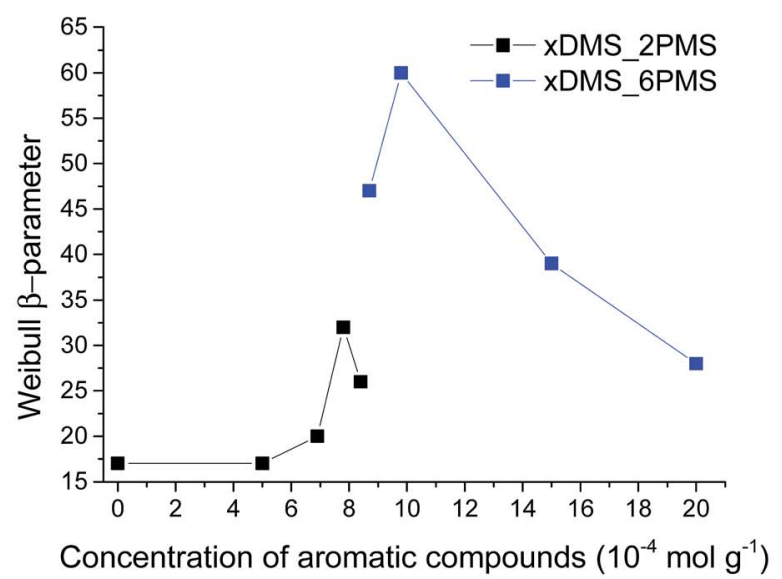

b

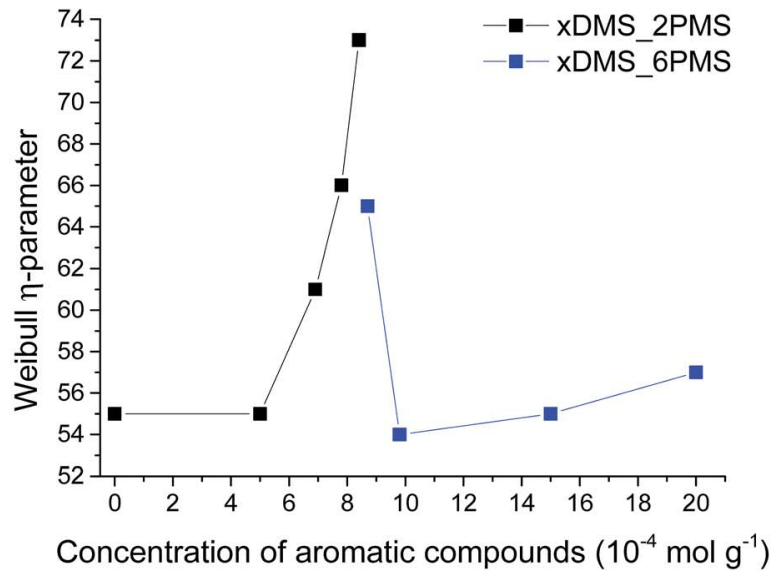

Fig. 11 Weibull parameters for prepared PDMS-PPMS copolymer and reference (DMS-H31) samples: (a) $\beta$-parameter and (b) $\eta$-parameter.

Furthermore no links between the Weibull parameters and the Young's moduli of the elastomers could be identified, as shown in ESI 8, Fig. S12.†

\section{Conclusion}

Inherently soft elastomers based on cross-linked PDMS-PPMS copolymers were synthesised successfully and proven to possess increased electrical breakdown strength, due to voltage stabilisation arising from aromatic groups of PPMS. Cross-linked copolymers with varying concentrations of aromatic groups were prepared from copolymers synthesised by varying the chain length of PDMS while maintaining the chain length of PPMS. The cross-linked copolymers possessed higher electrical breakdown strength than the pure PDMS-based reference elastomer, due to $\pi$-electrons of the aromatic group being capable of trapping charges. Aside from having high electrical breakdown strength, the cross-linked copolymers showed an increased storage modulus and low viscous loss, hence maintaining the network integrity of the dielectric elastomer. All cross-linked copolymers demonstrated strain-hardening behaviours. From the electrical breakdown strength, optimal phenyl group concentration was determined at approximately $8.4 \times 10^{-4} \mathrm{~mol}$ $\mathrm{g}^{-1}$. As a result of these properties, voltage-stabilised elastomers were synthesised. Further studies will hopefully uncover better voltage stabilisers, which would subsequently be a giant step toward producing reliable dielectric elastomer-based products.

\section{Acknowledgements}

The Malaysian Ministry of Education (MoE), Universiti Tun Hussein Onn Malaysia (UTHM) and Innovationsfonden Danmark are gratefully acknowledged for their funding.

\section{Notes and references}

1 F. B. Madsen, A. E. Daugaard, S. Hvilsted and A. L. Skov, Macromol. Rapid Commun., 2016, 37, 378-413.
2 P. Brochu and Q. Pei, Macromol. Rapid Commun., 2010, 31, 10-36.

3 R. Pelrine, R. Kornbluh, Q. Pei and J. Joseph, Science, 2000, 287, 836-839.

4 Z. Suo, Acta Mech. Solida Sin., 2010, 23, 549-577.

5 X. Zhao, W. Hong and Z. Suo, Phys. Rev. B: Condens. Matter Mater. Phys., 2007, 76, 134113.

6 Y. Liu, L. Liu, K. Yu, S. Sun and J. Leng, Smart Mater. Struct., 2009, 18, 95040.

7 L. Liu, Y. Liu, J. Leng and K. Lau, Smart Mater. Struct., 2011, 20, 115015.

8 S. Rosset and H. R. Shea, Appl. Phys. A: Mater. Sci. Process., 2013, 110, 281-307.

9 L. Yu and A. L. Skov, Int. J. Smart Nano Mater., 2015, 6, 268289.

10 S. Vudayagiri, S. Zakaria, L. Yu, S. S. Hassouneh, M. Benslimane and A. L. Skov, Smart Mater. Struct., 2014, 23, 105017.

11 Z. Zhang, L. Liu, J. Fan, K. Yu, Y. Liu, L. Shi and J. Leng, Proc. SPIE, 2008, 6926, 692610.

12 L. J. Romasanta, P. Leret, L. Casaban, M. Hernández, M. A. de la Rubia, J. F. Fernández, J. M. Kenny, M. A. Lopez-Manchado and R. Verdejo, J. Mater. Chem., 2012, 22, 24705-24712.

13 H. Böse, D. Uhl and R. Rabindranath, Proc. SPIE, 2012, 8340, $83402 \mathrm{E}$.

14 B. Kussmaul, S. Risse, G. Kofod, R. Waché, M. Wegener, D. N. McCarthy, H. Krüger and R. Gerhard, Adv. Funct. Mater., 2011, 21, 4589-4594.

15 F. B. Madsen, A. E. Daugaard, S. Hvilsted, M. Y. Benslimane and A. L. Skov, Smart Mater. Struct., 2013, 22, 1-11.

16 F. B. Madsen, I. Javakhishvili, R. E. Jensen, A. E. Daugaard, S. Hvilsted and A. L. Skov, Polym. Chem., 2014, 5, 7054-7061.

17 P. Mazurek, S. Hvilsted and A. L. Skov, Polymer, 2016, 87, 17.

18 P. Mazurek, L. Yu, R. Gerhard, W. Wirges and A. L. Skov, J. Appl. Polym. Sci., 2016, 133, 44153. 
19 S. M. Ha, W. Yuan, Q. Pei, R. Pelrine and S. Stanford, Adv. Mater., 2006, 18, 887-891.

20 P. Brochu, H. Stoyanov, X. Niu and Q. Pei, Smart Mater. Struct., 2013, 22, 55022.

21 F. B. Madsen, A. E. Daugaard, C. Fleury, S. Hvilsted and A. L. Skov, RSC Adv., 2014, 4, 6939-6945.

22 C. Tugui, G. Stiubianu, M. Iacob, C. Ursu, A. Bele, S. Vlad and M. Cazacu, J. Mater. Chem. C, 2015, 3, 8963-8969.

23 S. Zakaria, L. Yu, G. Kofod and A. L. Skov, Mater. Today Commun., 2015, 4, 204-213.

24 P. H. F. Morshuis and J. J. Smit, IEEE Trans. Dielectr. Electr. Insul., 2005, 12, 328-340.

25 K. H. Stark and C. G. Garton, Nature, 1955, 176, 1225-1226. 26 S. Zakaria, P. H. F. Morshuis, M. Y. Benslimane, K. V. Gernaey and A. L. Skov, Proc. SPIE, 2014, 9056, 90562V. 27 R. Kochetov, A. V. Korobko, T. Andritsch, P. H. F. Morshuis, S. J. Picken and J. J. Smit, J. Phys. D: Appl. Phys., 2011, 44, 395401.

28 S. Zakaria, P. H. F. Morshuis, M. Y. Benslimane, L. Yu and A. L. Skov, Smart Mater. Struct., 2015, 24, 55009.

29 A. Trols, A. Kogler, R. Baumgartner, R. Kaltseis, C. Keplinger, R. Schwodiauer, I. Graz and S. Bauer, Smart Mater. Struct., 2013, 22, 104012.

30 M. Kollosche, M. Melzer, A. Becker, H. Stoyanov, D. N. McCarthy, H. Ragusch and G. Kofod, Proc. SPIE, 2009, 7287, 728729 .
31 Y. Yamano and H. Endoh, IEEE Trans. Dielectr. Electr. Insul., 1998, 5, 270-275.

32 Y. Yamano, IEEE Trans. Dielectr. Electr. Insul., 2006, 13, 773781.

33 V. Englund, R. Huuva, S. M. Gubanski and T. Hjertberg, Polym. Degrad. Stab., 2009, 94, 823-833.

34 J. McMurry, Organic Chemistry, Brooks/Cole, California, 8th edn, 2011.

35 A. H. A. Razak, P. Szabo and A. L. Skov, RSC Adv., 2015, 5, 53054-53062.

36 M. A. Brook, H. U. Saier, J. Schnabel, K. Town and M. Maloney, Ind. Eng. Chem. Res., 2007, 46, 8796-8805.

37 S. Zakaria, F. B. Madsen and A. L. Skov, Polym.-Plast. Technol. Eng., 2016, DOI: 10.1080/03602559.2016.1211689.

38 A. L. Skov, A. G. Bejenariu, J. Bøgelund and M. Y. Benslimane, Proc. SPIE, 2012, 8340, 83400M.

39 Y. Luo, S. Tan, H. Wang, F. Wu, X. Liu, L. Li and Z. Zhang, Chem. Eng. J., 2008, 137, 496-502.

40 A. L. Larsen, K. Hansen, P. Sommer-Larsen, O. Hassager, A. Bach, S. Ndoni and M. Jørgensen, Macromolecules, 2003, 36, 10063-10070.

41 S. K. Nandi, X. Liu, D. K. Venkatachalam and R. G. Elliman, Phys. Rev. Appl., 2015, 4, 64010. 